\title{
Effects of the encircling procedure on the aqueous flow rate in retinal detachment eyes: a fluorometric study
}

\author{
MAKOTO ARAIE, YASUHIRO SUGIURA, KENSEI MINOTA, \\ AND KAZUMI AKAZAWA \\ From the Department of Ophthalmology, University of Tokyo School of Medicine, Tokyo, Japan
}

SUMMARY Fluorophotometry was carried out in nine cases of unilateral non-traumatic rhegmatogenous retinal detachment successfully treated by a combination of local buckling and an encircling procedure with a silicone band. After topical instillation of fluorescein the change in its concentration in the anterior chamber was followed, from which the loss rate of the dye from the anterior chamber $\left(k_{0}\right)$ and the cornea-aqueous transfer coefficient $\left(k_{\text {c.ca }}\right)$ were estimated. The thickness of the cornea and the anterior chamber volume were also measured, and the aqueous flow rate and the corneal endothelial permeability were calculated in individual eyes. The examinations performed $4-18$ months after operation showed that the aqueous flow rate in the operated eye fell to 85 (SD 12$) \%$ of that in the fellow control eye $(p<0.005)$. In the operated eye the anterior chamber volume also fell significantly, and the corneal endothelial permeability may have decreased. Ocular hypotension after the detachment surgery with encirclement was attributable to a decrease in the aqueous flow rate.

It is well documented that rhegmatogenous retinal detachment is usually associated with low intraocular pressure (IOP),' for which two mechanisms have been suggested: (1) reduced formation of the aqueous humour ${ }^{2-5}$ and (2) fluid outflow through the retinal break and choroid. ${ }^{6-8}$ But it has also been reported that the IOP in an eye with rhegmatogenous retinal detachment remained lower than in the healthy fellow eye after the retina was reattached successfully. ${ }^{910}$ The encircling procedure produced more pronounced and long-standing postoperative ocular hypotension. "10 Furthermore, Friedman and Neumann reported that in 11 out of 12 eyes with primary open-angle glaucoma after the rhegmatogenous retinal detachment was successfully operated the IOP decreased for 1 to 5.5 years without any antiglaucoma treatment, while it was still necessary to control the IOP in all 12 fellow eyes." Similar findings have been reported by several authors, and they are compatible with the above observation. ${ }^{12-14}$

The mechanism of the low IOP in the successfully treated eye with retinal detachment has not been fully studied yet. To the best of our knowledge only a

Correspondence to Dr Makoto Araie, Department of Ophthalmology, University of Tokyo School of Medicine, 7-3-1, Hongo, Bunkyo-ku, Tokyo 113, Japan study using tonography has been reported, which suggested it should be attributed to reduced aqueous humour formation." However, as the ocular rigidity was altered after the retinal detachment surgery, especially after operations with an encircling procedure, 4111516 the apparent aqueous flow rate estimated from the apparent facility of outflow, without a correction for the effect of ocular rigidity, would need cautious interpretation. In the present report, the aqueous humour dynamics in successfully treated cases of unilateral, non-traumatic, rhegmatogenous retinal detachment were studied by fluorometry, which is now believed to give the truest information on the aqueous flow rate in the living eye..$^{178}$

\section{Materials and methods}

\section{SUBJECTS}

Nine patients with unilateral, non-traumatic, rhegmatogenous retinal detachment aged 21 to 65 years were included in this study (Table 1). They were operated upon in the University of Tokyo Branch Hospital from February to December 1982 by one of the authors (KM) with a combination of equator parallel scleral buckling using a silicone strip 
Table 1 Data of subjects

\begin{tabular}{|c|c|c|c|c|c|}
\hline Subject & Age & Sex & $\begin{array}{l}\text { Extent of detachment } \\
\text { (quadrant) }\end{array}$ & $\begin{array}{l}\text { Area of exoplant } \\
\text { (degree) }\end{array}$ & $\begin{array}{l}\text { Period }{ }^{*} \\
\text { (month) }\end{array}$ \\
\hline 1 & 53 & $\mathbf{M}$ & 3 & $90^{\circ}+$ encircling & 4 \\
\hline 2 & 49 & $\mathbf{F}$ & 2 & $150^{\circ}+$ cncircling & 6 \\
\hline 3 & 40 & $M$ & 4 & $180^{\circ}+$ cncircling & 5 \\
\hline 4 & 45 & $M$ & 1 & $90^{\circ}+$ encircling & 8 \\
\hline 5 & 55 & $\mathrm{M}$ & $i$ & $60^{\circ}+$ encircling & 7 \\
\hline 6 & 65 & $\mathbf{F}$ & 4 & $90^{\circ}+$ encircling & 7 \\
\hline 7 & 64 & $\mathbf{F}$ & 2 & $120^{\circ}+$ encircling & 7 \\
\hline 8 & 21 & $\mathrm{~F}$ & 4 & $90^{\circ}+$ encircling & 18 \\
\hline 9 & 61 & $\mathbf{M}$ & 2 & $90^{\circ}+$ encircling & 7 \\
\hline
\end{tabular}

* Period between surgery and fluorometry.

exoplant (No.31s or 32s) and an encircling procedure using a silicone band (No.240s) (Medical Instrument Research Associates Inc., Waltham, Mass); tightening of the encircling band was adjusted to give an indentation of about $1 \mathrm{~mm}$. All retinal breaks were sealed by cryopexy or postoperative photocoagulation, and no diathermy was used. In all cases the retina was successfully reattached at the first operation, and no significant complications during the operation or during postoperative follow-up were encountered. The fundus examination of the fellow eyes revealed peripheral retinal degenerations but no retinal tears or holes. The patients had no ocular and systemic disorders other than retinal detachment.

\section{FLUOROMETRY}

The fluorometric examination was carried out four to 18 months (eight months on an average) after the surgery. Before the fluorometric measurement was carried out informed written consent was obtained from each subject. At 9 am a $15 \mu$ l of $30 \%$ sterile solution of sodium fluorescein was gently instilled on to the cornea of both eyes. The subjects were asked to blink several times and then to keep their eyes closed for about one minute. Five minutes after the instillation the conjunctival cul-de-sac was washed throughly with physiological saline. The fluorescence intensities in the central part of the cornea and the anterior chamber were then measured every hour for seven hours with a slit-lamp fluorometer (Tokyo Optical Co. Ltd., Tokyo, Japan) and the fluorescein concentrations in the anterior chamber were determined by correcting the influence of the fluorescence in the cornea on that in the anterior chamber as previously described. ${ }^{19}$ At two hours after the instillation the thickness of the cornea (CT) was measured with a Haag-Streit pachymeter modified by Mishima, ${ }^{20}$ and at four hours the anterior chamber was photographed according to the method of Johnson et al. ${ }^{21}$ The anterior chamber depth was read from the photograph by means of a standardised anterior chamber scale and the volume of the anterior chamber was calculated." At the end of the fluorometric measurements the anterior segment of the eye was examined in detail by slit-lamp microscope, and the IOP was measured with a Goldmann applanation tonometer. All measurements and examinations were carried out by one of the authors (MA) without knowing the laterality of the previous history of retinal detachment.

\section{METHOD OF DATA ANALYSIS}

As the method of calculating the aqueous flow rate from the change in concentration of fluorescein in the anterior chamber was described in detail previously, ${ }^{19}$ only a brief outline will be given.

According to the two-compartment model of Jones and Maurice, ${ }^{11}$ the concentration change in the anterior chamber after a single dose to the cornea can be written as follows: ${ }^{172}$

$\mathrm{C}_{\mathrm{a}}=\left(\mathrm{M}_{\mathrm{o}} / \mathrm{V}_{\mathrm{a}}\right)\left(\mathrm{k}_{\mathrm{c} . \mathrm{ca}} /(\mathrm{B}-\mathrm{A})\right)(\exp (-\mathrm{At})-\exp (-\mathrm{Bt})) . .(1)$

where $A$ is equal to $\left\{\left(k_{\mathrm{a} . \mathrm{ac}}+\mathrm{k}_{\mathrm{c} . \mathrm{cal}}+\mathrm{k}_{\mathrm{o}}\right)-\right.$

$\sqrt{\left.\left(\mathrm{k}_{\mathrm{a} . \mathrm{ac}}+\mathrm{k}_{\mathrm{c} . \mathrm{ca}}+\mathrm{k}_{\mathrm{o}}\right)^{2}-4 \mathrm{k}_{\mathrm{c} . \mathrm{cat}} \mathrm{k}_{\mathrm{o}}\right\}} / 2$, and $B$ is equal to $\left\{\left(k_{\text {a. ac }}+k_{\text {c.cat }}+k_{o}\right)+\right.$

$\sqrt{\left.\left(k_{\text {a. ac }}+k_{\text {c.cal }}+k_{o}\right)^{2}-4 k_{\text {c.ca }} k_{o}\right\}} / 2$,

and $k_{\mathrm{a} . \text { ac }}$ is equal to $\left(\mathrm{V}_{\mathrm{c}} \mathrm{r}_{\mathrm{ca}} / \mathrm{V}_{\mathrm{a}}\right) \mathrm{k}_{\mathrm{c.c \textrm {ca }}} .2$ The symbols used here are: $C_{a}$, the mean concentration in the anterior chamber; $M_{o}$, the amount in the cornea at time $0 ; \mathrm{k}_{\mathrm{a} . a c}$, the aqueous-cornea transfer coefficient in reference to the anterior chamber volume; $\mathbf{k}_{\mathrm{c} . \mathrm{ca}}$, the cornea-aqueous transfer coefficient in reference to the corneal volume; $k_{0}$, the loss rate from the anterior chamber; $V_{c}$, the volume of the cornea; $V_{a}$, the volume of the anterior chamber; $r_{c a}$, the corneaaqueous distribution ratio. ${ }^{22}$ The values of $k_{\text {c.ca }}$ and $\mathbf{k}_{\mathrm{o}}$ were estimated from the obtained data series of the fluorescein concentration in the anterior chamber, $C_{a}$, by means of Marquardt's method of least squares fitting applied to equation 1 using a M-280H computer (Hitachi Electric Co., Tokyo)..$^{19.3}$ 
Table 2 Results of measurements

\begin{tabular}{|c|c|c|c|c|c|c|c|c|}
\hline \multirow[t]{2}{*}{ Subject } & \multicolumn{2}{|c|}{$I O P(\mathrm{mmHg})$} & \multicolumn{2}{|c|}{ Anterior chamber depth ( $\mathrm{mm})$} & \multicolumn{2}{|c|}{$V_{u}(\mu)$} & \multicolumn{2}{|c|}{$C T(\mathrm{~mm})$} \\
\hline & $O p$ & $F$ & $O p$ & $\boldsymbol{F}$ & $O p$ & $F$ & $O p$ & $F$ \\
\hline 1 & 13 & 15 & 3.0 & 3.4 & 174 & 242 & 0.52 & 0.52 \\
\hline 2 & 18 & 17 & $3 \cdot 3$ & $3 \cdot 8$ & 185 & 218 & 0.51 & 0.50 \\
\hline 3 & 10 & 8 & $3 \cdot 2$ & $3 \cdot 5$ & 208 & 243 & 0.51 & 0.51 \\
\hline 4 & 8 & 14 & $2 \cdot 8$ & $3 \cdot 0$ & 177 & 183 & 0.52 & 0.53 \\
\hline 5 & 14 & 16 & $3 \cdot 1$ & 3.4 & 203 & 206 & 0.52 & 0.52 \\
\hline 6 & 16 & 12 & $2 \cdot 5$ & $2 \cdot 7$ & 136 & 153 & 0.52 & 0.51 \\
\hline 7 & 10 & 12 & 1.9 & $2 \cdot 0$ & 82 & 86 & 0.52 & 0.52 \\
\hline 8 & 10 & 14 & $2 \cdot 5$ & $2 \cdot 7$ & 150 & 176 & 0.52 & 0.52 \\
\hline 9 & 9 & 16 & $2 \cdot 8$ & $3 \cdot 0$ & 144 & 161 & 0.51 & 0.51 \\
\hline Mean & 12 & 14 & $2 \cdot 6$ & $3 \cdot 1$ & 162 & 185 & 0.52 & 0.51 \\
\hline S.D & 3 & 3 & 0.9 & $0 \cdot 5$ & 39 & 50 & $0 \cdot 01$ & $0 \cdot 01$ \\
\hline
\end{tabular}

Op $=$ operated eye. $F=$ fellow control cye. For explanation of $V_{a}$ and CT sec text.

In carrying out the calculation the measured volume of the anterior chamber was used as $V_{a}, V_{c}$ was assumed to be $70 \mu 1,,^{24}$ and $r_{c a}$ was assumed to be $1 \cdot 7 .^{20}$

\section{Results}

The results of the measurements are summarised in Table 2 and the results of the calculations in Table 3. The aqueous flow rate was calculated by $k_{o} \times V_{a},{ }^{17}$ and the corneal endothelial permeability coefficient $\left(P_{a c}\right)$ was calculated by $k_{c . c a} \times r_{c a} \times 0.9 \times C T .{ }^{20}$

No significant difference was seen between both eyes in the IOP and CT (paired $t$ test, $\mathrm{p}>0 \cdot 1$ ). On the other hand the aqueous flow rate $(p<0.005), V_{a}$ and the depth of the anterior chamber $(p<0.01)$ were significantly lower in the operated eyes. The ratio of operated eye to fellow eye averaged 0.85 (SD 0.12) for the aqueous flow rate and 0.91 (SD 0.10) for $P_{\text {ac }}$ $(n=9)$. When these ratios were compared with the left-right ratios for the aqueous flow rate and the $\mathrm{P}_{\mathrm{ac}}$ obtained in normal Japanese - 0.99 (SD 0.05) for each $(n=11)^{19}$ - the ratio of operated eye to fellow eye for aqueous flow rate was significantly lower than the left-right ratio obtained in normal persons (unpaired $t$ test, $\mathrm{p}<0 \cdot 005$ ), but that for $P_{\mathrm{ac}}$ was not significantly different from the left-right ratio obtained in normal persons $(p>0.05)$. The anterior segment of the eye appeared to be normal on slit-lamp microscopic examination.

\section{Discussion}

\section{METHOD}

The present method of calculation needs the value of $r_{c a}$, which was assumed to be 1.7 according to the result obtained after systemic administration of fluorescein. ${ }^{20}$ However, recent studies showed that systemically administered fluorescein is rapidly metabolised to fluorescein glucuronide, and most of

Table 3 Results of calculations

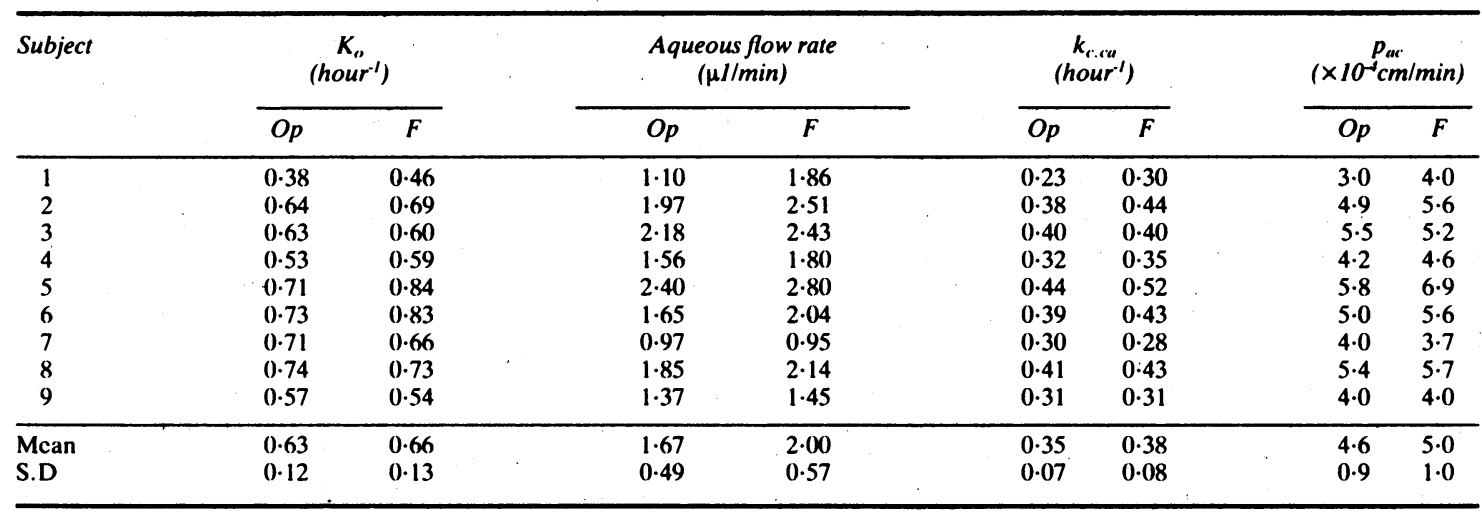

Op $=$ operated cyc. $F=$ fellow control cyc. For explanation of $k_{\mathrm{o},}, k_{\mathrm{c} . \mathrm{ta}}$, and $\mathrm{P}_{\mathrm{ic}}$ sec text 
the fluorophore in the plasma or in the anterior chamber after systemic administration of the dye is not fluorescein itself but fluorescein glucuronide. ${ }^{25 \cdot 27}$ This compound is also fluorescent, though more weakly than fluorescein is..$^{25}{ }^{25}$ Thus it is possible that the value of $r_{c a}$ determined after systemic fluorescein mainly reflected that of fluorescein glucuronide rather than fluorescein. Indeed in the rabbit cornea the value of $r_{c a}$ determined after exclusion of the influence of fluorescein glucuronide was twice as great as that determined after systemic fluorescein. ${ }^{2 k}$ As the estimates for $k_{o}$ and $k_{c . c a}$ calculated by the present method were influenced by variation in the $r_{c a}$ value, ${ }^{17}$ it is probable that the estimates obtained here are somewhat different from the 'true' value of $k_{o}$ and $k_{c . c a}$ for fluorescein. The value of $r_{c a}$, which is thought to reflect binding of the dye to the stromal tissue $^{21}$ should have no significant individual variations in the normal cornea, and the values for fellow eyes showed no significant difference. ${ }^{21}$ Thus the influence of a variation in $r_{\mathrm{ca}}$ values on the calculation must be very similar in both eyes of an individual, and it is justifiable to compare the values of $k_{o}$ and $k_{\text {c.ca }}$ determined by the present method in both eyes to examine the difference between the 'true' $k_{o}$ and $\mathbf{k}_{\text {c.ca. }}$.

The value of $k_{0}$. is expressed by the sum of the values of the transfer coefficient by flow $\left(\mathrm{k}_{\mathrm{fa}}\right)$ and by diffusion $\left(\mathrm{k}_{\text {d.pa }}\right) .{ }^{172}$ As $\mathrm{k}_{\mathrm{fa}}$ accounts for more than $90 \%$ of $k_{o},{ }^{1725}$ the aqueous flow rate, $k_{f a} \times V_{a}$, was approximated by $k_{o} \times V_{a}$ in the present study. $A$ decrease in the $k_{0}$ found in the operated eye may be interpreted as being due to a decrease in the $k_{d . p a}$ rather than a decrease in the $k_{\mathrm{fa}}$. However, it seems quite unlikely that the value of $k_{d . p a}$, an index of the blood-aqueous barrier permeability, was lower in the operated eye than in the fellow unoperated eye, though no fluorometric measurements after systemic fluorescein were carried out in the present study. An increase in the blood-aqueous barrier permeability, if any, would give a rise in the value of $k_{o}$, but not in reduction.

\section{AQUEOUS FLOW RATE}

The aqueous flow rate in the operated eye was decreased to $85 \%$ of that in the fellow eye and the reduction in the aqueous flow rate was thought to be responsible for the well documented postoperative ocular hypotension after retinal detachment surgery with an encircling procedure. " ${ }^{11}$ The method used to measure the aqueous flow rate in this study estimates the rate of the aqueous humour movement through the anterior chamber, but does not estimate the rate of the aqueous humour formation into the posterior chamber. The lower aqueous flow rate observed in the present subjects may be explained by either one or both of the following two mechanisms: (1) reduction in the net aqueous humour formation or (2) increase in posteriorly directed outflow of the aqueous humour.

It is well documented that the scleral buckling procedures, especially that with encirclement, are followed by shallowing of the anterior chamber in the early postoperative period. ${ }^{20.31}$ This shallowing is probably attributable to the change in the ciliary body and zonule due to the compromised blood drainage from the ciliary body caused by the scleral buckle. ${ }^{31-33}$ The blood leaving the ciliary body is mainly drained into the vortex veins, and, in the monkey eye, if three or four vortex veins are injured, the ciliary body became markedly congested. ${ }^{32}$ In the rabbit eye an encircling procedure reduced the ciliary blood flow, probably owing to compromised venous drainage. ${ }^{34}$ A postoperative change in the flow characteristics of the blood was reported in the eye which underwent an encircling procedure." Under these conditions it seems likely that the function of the ciliary epithelium is also affected, resulting in the reduction of the aqueous humour formation. In the present subjects the anterior chamber depth was $16 \%$ shallower in the operated eye than in the fellow eye. This fact suggests that the ciliary body in the operated eye of the present subjects was still not in a normal physiological condition, having not fully recovered from the postoperative changes. This favours the explanation that the reduced aqueous humour formation was mainly responsible for the reduced aqueous flow rate observed.

On the other hand there is increasing evidence that, in the eye with rhegmatogenous retinal detachment, a fluid flow exists from the posterior chamber through the vitreous cavity and retinal breaks and across the retinal pigment epithelium. ${ }^{735: 37}$ But at the present stage of investigation no information is available on the question whether it still exists after the retina is reattached surgically. The intact retina is a barrier to the movement of water across it. ${ }^{3 .}$ The retina undergoes structural changes when it is detached, but it restores normal morphology and also probably its resistance against the movement of water, after the detachment is surgically repositioned. ${ }^{31+11}$ The retinal break on the other hand is thought to remain as a defect in the retina even after surgical reattachment.

Furthermore, the diffusion of peroxidase was greater across the photocoagulated scarred retina than across the normal retina." Thus it is possible that the fluid outflow from the posterior chamber through the scarred retinal break and choroid exists also after the retina is reattached. If this is the case, the postoperative decrease in the aqueous flow through the anterior chamber and the resultant 
ocular hypotension are likely to be of long duration, because a window in the barrier against water movement would remain almost as permanently as the scarred retinal breaks, and the encirclement itself should have little influence on the postoperative IOP.

However, it is known that ocular hypotension after retinal detachment surgery gradually decreases and that encirclement produces more pronounced and long-standing postoperative IOP change. ${ }^{910}$ These facts suggest that this postoperative IOP change is associated with some non-physiological changes in the eye caused by surgery which gradually disappear postoperatively. Since the postoperative change in the anterior chamber depth also improves gradually, ${ }^{24.31}$ it seems likely that the postoperative ocular hypotension is related to the postoperative congestion and swelling of the ciliary body, and resultant reduced formation of aqueous humour, rather than the fluid outflow through the scarred retina.

\section{CORNEAL ENDOTHELIAL PERMEABILITY}

The corneal endothelial permeability coefficient, $P_{a c}$, to fluorescein is a quantitative index of the barrier function of the corneal endothelium. ${ }^{21}$ The value of $P_{a c}$ appeared to be lower in the operated eye than in the fellow eye of the present subjects. However, no significant difference was seen between the ratio of operated eye to fellow eye and the left-right ratio found in normal persons. Consequently it is difficult to draw a conclusion on the $P_{a c}$ difference observed here, because of the variability of $P_{a c}$ measured by this technique used at present and also the variability of $P_{a c}$ between the right and left eyes of normal persons. The value of $P_{a c}$ in the normal persons as measured by this method" was significantly smaller than the values obtained both in the operated and the fellow eyes of the present subjects (unpaired $t$ test, $p<0.05)$. It has been reported that the fellow eye in cases of unilateral rhegmatogenous retinal detachment had a decreased IOP and abnormal tonographic findings, suggesting some underlying pathology in these eyes. ${ }^{5+2+3}$ Although the difference in the $P_{a c}$ found here was not highly significant, it may suggest that the corneal endothelium is functionally not completely normal in patients with non-traumatic rhegmatogenous retinal detachment.

\section{References}

1 Leydhecker W. Glaukom: ein Handbuch. New York: Springer, 1973: 46-7.

2 Dobbic JG. A study of the intraocular fluid dynamics in retinal detachment. Arch Ophthalmol 1963; 69: 159-64.

3 Regan CDJ, Rousscau AP. The intraocular dynamics of cyes with retinal detachment. Am J Ophthalmol 1966; 61: 696-702.

4 Foulds WS. Experimental detachment of the retina and its effects on the intraocular fluid dynamics. Mod Probl Ophthalmol 1969; 8: 51-63.
5 Langham ME, Regan CDJ. Circulatory changes associated with onset of primary retinal detachment. Arch Ophthalmol 1969;81: 820-9.

6 Bcigelman MD. Acute hypotony in retinal detachment. Arch Ophthalmol 1929; $1: 463-7$.

7 Cantrill HL, Pederson JE. Experimental retinal detachment. 3. Vitreous fluorophotometory. Arch Ophthalmol 1982; 100: 1810-3.

8 Pederson JE. Experimental retinal detachment. 4. Aqueous humor dynamics in rhegmatogenous detachments. Arch Ophthalmol 1982; 100: 1814-6.

9 Syrdalen P. Intraocular pressure and ocular rigidity in patients with retinal detachment. Postoperative study. Acta Ophthalmol (Kbh) 1970; 48: 1036-44.

10 Dobbic JG. Circulatory changes in the eye associated with retinal detachment and its repair. Trans Am Ophthalmol Soc 1980; 78: 503-66.

11 Friedman Z, Neumann E. Effect of retinal detachment surgery on the course of preexisting open-angle glaucoma. Am J Ophthalmol 1975; 80: 702-5.

12 Sebestyen JG, Schepens CL, Rosenthal ML. Retinal detachment and glaucoma. 1. Tonometric and gonioscopic study of 160 cases. Arch Ophthalmol 1962; 67: 736-45.

13 Sarin LK, Chessen GJ, McDonald PR. The problem of retinal detachment in the pressure of glaucoma. Am J Ophthalmol 1963; 56: 908-11.

14 Lawton-Smith J. Retinal detachment and glaucoma. Ophthalmology 1963; 67: 726-32.

15 Harbin TS, Laikam SE, Lipsitt K, Jarret WH, Hagler WS. Applanation-Schiøtz disparity after retinal detachment surgery utilizing cryopexy. Ophthalmology 1979; 86: 1609-11.

16 Pemberton JW. Schiøtz-applanation disparity following retinal detachment surgery. Arch Ophthalmol 1969; 81: 534-7.

17 Jones RF, Maurice DM. New methods of measuring the rate of aqueous flow in man with fluorescein. Exp Eye Res 1966; 5: 208-20.

18 Mishima S. Ocular effects of beta-adrenergic agents. Surv Ophthalmol 1982; 27: 187-208.

19 Araie M. Kinetics of intraocular penetration by topical fluorescein: analysis by new method. Jpn J Ophthalmol 1983; 27: 420-32.

20 Mishima S. Clinical investigations on the corneal endothelium. Am J Ophthalmol 1982; 93: 1-29.

21 Johnson SB, Coakes RL, Brubaker RF. A simple photogrammetric method of measuring anterior chamber volume. Am J Ophthalmol 1978; 85: 469-74.

22 Mishima S. Clinical pharmacokinetics of the eye. Invest Ophthalmol Vis Sci 1981; 21: 504-41.

23 Marquardt DW. An algorithm for least-square estimation of nonlinear parameters. J Soc Ind Appl Math 1963; 11: 431-41.

24 Maurice DM. The cornea and sclera. In: Davson H, ed. The eye. New York: Academic Press, 1969; 1: 489-600.

25 Araie M, Sawa M, Nagataki, Mishima S. Aqueous humor dynamics in man as studied by oral fluorescein. Jpn J Ophthalmol 1980; 24: 346-62.

26 Grotte D, Mattox V, Brubaker RF. Fluorescent, physiological, and pharmacokinetic properties of fluorescein glucuronide. Exp Eye Res 1985; 40: 23-33.

27 Seto C, Araie M, Takase M. Study of fluorescein glucuronide II. A comparative ocular kinetic study of fluorescein and fluorescein glucuronide. Graefes Arch Clin Exp Ophthalmol 1986; 224: 113-7.

28 Araie M. Maurice DM. A reevaluation of corneal endothelial permeability to fluorescein. Exp Eye Res 1985; 41: 384-90.

29 Fiore JV, Newton JC. Anterior segment changes following the scleral buckling procedure. Arch Ophthalmol 1970; 84: 284-7.

30 Hartley RE, Marsh RJ. Anterior chamber depth changes after retinal detachment. BrJ Ophthalmol 1973; 57: 546-50.

31 Phelps CD. Glaucoma associated with retinal disorders. In: 
Ritch R, Shiclds MB, cds. The sccondary glaucomas. London: Mosby, 1982: 150-61.

32 Hayreh SS, Baines JAB. Occlusion of the vortex veins. An experimental study. Br J Ophthalmol 1973; 57: 217-38.

33 Aaberg TM, Maggiano JM. Choroidal edema associated with retinal detachment repair: experimental and clinical correlation. Mod Probl Ophthalmol 1979; 20: 6-15.

34 Diddic KR. Ernest JT. Uveal blood flow after $360^{\circ}$ constriction in the rabbit. Arch Ophthalmol 1980; 98: 729-30.

35 Pederson JE, Cantrill HL. Experimental retinal detachment. 5. Fluid movement through the retinal hole. Arch Ophthalmol 1984; 102: 136-9.

36 Cambell DG. Iris retraction associated with rhegmatogenous retinal detachment syndrome and hypotony. A new explanation. Arch Ophthalmol 1984; 102: 1457-63.

37 Tsuboi S, Taki-Noie J, Emi K, Manabe R. Fluid dynamics in eyes with rhegmatogenous retinal detachment. Am J Ophthalmol 1985; 99: 637-76.
38 Fatt I, Shantinath K. Flow conductivity of retina and its role in retinal detachment. Exp Eye Res 1971; 12: 218-26.

39 Kroll AJ, Machemer R. Experimental retinal detachment and rcattachment: 2. Electron microscopy. Mod Probl Ophthalmol 1969;8: 91-105.

40 Machemer R, Norton EWD. Experimantal retinal detachment and reattachment: 1: Mcthods, clinical picture and histology. Mod Probl Ophthalmol 1969; 8: 80-90.

41 Peyman GA, Spitznas M, Straatsma BR, Pcroxidase diffusion in the normal and photocoagulated retina. Invest Ophthalmol Vis Sci 1971; 10: 181-9.

42 Syrdalen $P$. Intraocular pressure and ocular rigidity in patients with retinal detachment. 1. Preoperative study. Acta Ophthalmol (Kbh) 1970; 48: 1024-35.

43 Rousseau AP, Regan CDJ. Pressurc cup studics in cyes with retinal detachment. Arch Ophthalmol 1965; 73: 803-9.

Accepted for publication 15 August 1986. 